\title{
A Systematic Review of Research on Anti-disaster Capability in Urban Disaster
}

\author{
Liu Jie ${ }^{1}$, Shu Shichang ${ }^{1}$, Lin Xunguo ${ }^{2}$ and Shi Zhenwu ${ }^{{ }^{*}}$ \\ ${ }^{1}$ School of Civil Engineering, Northeast Forestry University, Harbin 150040, China \\ ${ }^{2}$ Office of Safety Systems, Civil Aviation Safety Authority, Canberra 2601, Australia
}

Received 19 March 2017; Accepted 28 September 2017

\begin{abstract}
Since the 20th century, the number of disasters, economic losses, and people affected by disasters occurred in cities all over the world has been increasing significantly due to increased contradictions in population, resources, and the environment. Therefore, anti-disaster capability as the core concept of research on urban sustainable development has become a common concern in many disciplines, such as ecology, disaster management, and climate change. To summarize the basic connotations, characteristics, and quantitative assessment methods of anti-disaster capability in urban disaster, and to extract its context and development trend, our study analyzed the concept and characteristics of anti-urban disaster capability, examined the mutual relationship among anti-disaster capability, adaptation, vulnerability, and resilience, and reviewed the concepts of and assessment research on three concentrated fields (i.e., adaptation, vulnerability, and resilience) on the basis of global literature on anti-disaster capability. On this basis, our study then analyzed the main problems in current research on anti-disaster capability, overlooked the key issues and the future research direction of anti-disaster capability. The findings will provide an important technical reference for the implementation of integrated disaster management and mitigation measures.
\end{abstract}

Keywords: Disaster, Anti-disaster capability, Vulnerability, Adaptation, Resilience

\section{Introduction}

Over the past century, low-frequency and high-consequence disasters occurred worldwide have dramatically increased. Meanwhile, climate change has caused the natural disasters more unpredictable, unbalanced, and fatal. The meaning of "natural disasters" has constantly changed from a historical viewpoint[1]. From "acts of God" and "forces of nature" to "acts of men", scientific researchers have realized that disasters are no longer the product of purely natural phenomena but are the result of a combination of natural and human-built environment systems[2]. Cities as the center of politics, economy, and culture have provided many employment opportunities. They possess numerous other characteristics, such as population concentration, large number of buildings, and interconnection of various types of infrastructures. These characteristics allow cities to operate normally and become livable. However, they have also exposed the risk of new disasters to emerge and change constantly. Different from the risk of traditional disasters, the characteristics of the risk of new disasters are extreme, systematic, and unknown. The destructive power is often high which may cause serious human casualties, property damage, and social disorder in a country or region[3]. Furthermore, these characteristics make it difficult to predict the risk of new disasters. Emergency disaster management systems, which are characterized by the classified, staged, and graded emergencies, are often difficult to deal with such disasters effectively. Deo et al. reported that the rapid

*E-mail address: shizhenwu@126.com

ISSN: $1791-2377$ C 2017 Eastern Macedonia and Thrace Institute of Technology. All rights reserved. doi:10.25103/jestr.105.22 development of cities, to a large extent, not only transformed hazards into disasters or even catastrophes, but also led to the increase in the probability that these cities will be exposed to the risk of new disasters[4]. The urgent questions that should be addressed by policymakers and researchers when faced with these global and complex natural or even man-made disasters are as follows: How can anti-disaster capability be established and improved? What are the characteristics of anti-disaster capability the cities should have? Addressing these problems has presented practical significance to improve the comprehensive disaster management capacity of cities.

The rise of research on anti-disaster capability in urban disaster provides a new means to solve these problems. When a disaster occurs, an urban system with a strong antidisaster capability can adapt to and quickly recover from the disaster, and make the main social systems continue to function to avoid large-scale losses. Therefore, from the effectiveness and sustainability of disaster prevention and environmental governance, it will present practical significance in improving the capability of urban systems to resist and cope with disasters in the future by clarifying the context, international trend and development direction of research on anti-disaster capability in urban disaster, and combining concrete implementation methods in civil engineering and urban planning. However, many studies and practices lack a clear unified definition of anti-disaster capability[5]. Therefore, in the background of sustainable development strategies, our study analyzed and summarized research results on anti-disaster capability in recent years[6] and examined the theoretical system of and research results on anti-disaster capability in view of urban disaster management, including the concept and characteristics of anti-disaster capability, influencing factors, and evaluation 
research. Then, through practical application to real-world scenarios, our study discussed research changes in the theories, methods, and contents of anti-disaster capability in urban disaster to promote research on the same area and provide a new perspective to solve problems in the study of anti-disaster capability in urban disaster and risk management under disaster-prone conditions.

\section{Concept of anti-disaster capability}

The concept of anti-disaster capability, which originated from disaster risk research, is the key to resolve the complex and uncertain interactions between human-built and natural environment systems. In the related research of disaster risk, Schipper et al. originally defined disaster risk as the occurrence probability of a natural event multiplied by its consequence[7]. At the end of the 20th century, O'Keefe et al. indicated that disaster risk was an accumulation process and that the effects of disasters resulted in prominent imbalance in different countries[8]. The main reason for this imbalance was the interaction of the inherent attributes of a city itself that caused it to be vulnerable to disasters. Thus, the concept of anti-disaster capability, which is defined as the uncertainty of future urban disaster losses that emerge from the evolution of the urban system itself, is proposed. Anti-disaster capability is used to assess the capabilities of urban systems to resist, restore, adapt, and learn when they are faced with the impacts of disasters. Such a capability is mainly formed by the coupling effects of three inherent attributes of the urban systems, namely, vulnerability, resilience, and adaptation, which has motivated the study on disaster risk to reach a new dimension.

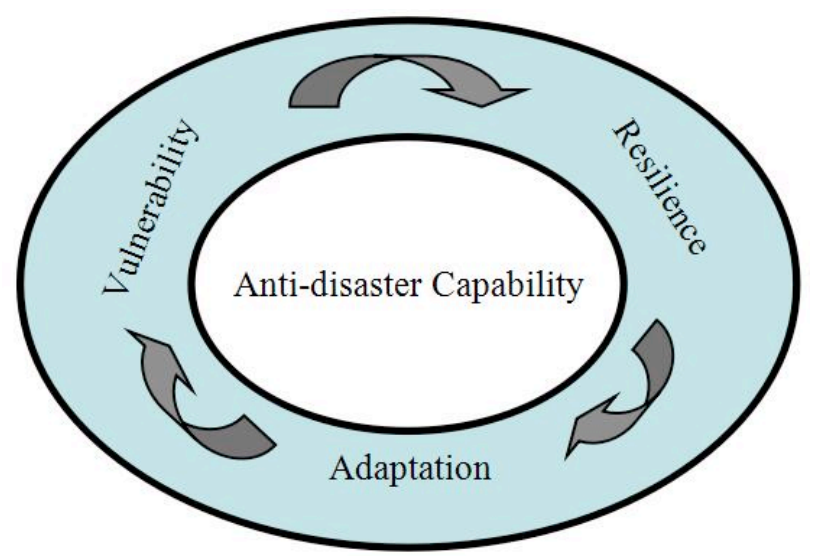

Fig. 1. Conceptual framework of anti-disaster capability

However, different research institutions focus on different points of anti-disaster capability research[9] and define different concepts of such a capability, which result in the high plasticity of the concept and indicate considerable divergence in research on anti-disaster capability. The study of this concept in various existing literature has no definite main line because the concept of anti-disaster capability is unclear and inconsistent. In particular, anti-disaster capability has been consistently associated with the complexity of urban systems and the evolution of complex problems corresponding to these complex systems. This condition makes the definition of anti-disaster capability highly complex and diverse, which prevents the establishment of a unified definition of anti-disaster capability. For example, Stern et al. argued that anti-disaster capability was "the capacity of a community or a city which exposed to disasters could effectively resist, absorb, adapt to and recover from those disasters in time by protecting and restoring the basic structures and functions" and stated that anti-disaster capability was an important goal of disaster reduction measures[10]. Aldrich believed that anti-disaster capability was the capacity to respond to disaster disturbances actively and defined the concept as "the capacity of the communities or cities which could adapt to disaster disturbances $\cdots$ and with the high anti-disaster capability, they could continue to function or recover quickly during- or post-disasters $\cdots$ and the communities or cities were able to endure disasters and recover from disasters"[11]. Current academic research on defining antidisaster capability generally presents the following main tendencies.

(1) Emphasizing that anti-disaster capability is an inherent attribute of a system.

Pomeroy et al. reported that anti-disaster capability was the capability to cope with the danger of disasters and recover after the unpredictable risk of disasters changed from invisible to visible[12]. Jongman et al. stated that antidisaster capability was the capability of a system to absorb damage or reduce the destructive forces of disasters before structural changes[13]. In addition, Yang believed that antidisaster capability was the capacity of an organization or individual to deal with a major or rare disaster[14]. Gaillard defined anti-disaster capability as an important feature of individuals, groups, organizations, and systems as a whole to deal with catastrophic disasters, it could keep the main functions of the system or organization operating normally[15].

(2) Emphasizing that anti-disaster capability is the capability of a system to adapt to disasters.

Tyhurst suggested that anti-disaster capability was the capability of individuals or organizations to quickly and actively design and implement adaptive actions which were compatible with the current environment[16]. Chang et al. believed that anti-disaster capability was the capability of a system to actively adapt to disaster damages and recover from destruction[17].

(3) Emphasizing that anti-disaster capability is the postdisaster recovery capability of a system.

Michelkerjan argued that anti-disaster capability was "the ability to restore the economy to the pre-disaster level in several months or a year" and emphasized the importance of the participation of a community in disaster recovery and preparedness[18]. Cimellaro et al. stated that a system required high anti-disaster capability to allow its economy and society to quickly recover and achieve "new normalcy" after disasters, and the formation of the high anti-disaster capability of the urban system was highly dependent on the pre-disaster collective decision-making capacity of the entire city[19].

(4) Emphasizing that anti-disaster capability is the learning capability of a system.

Rawls et al. argued that anti-disaster capability was used to describe a system's capacity for self-recovery and selfsufficiency to learn and grow[20]. Godschalk et al. illustrated that part of the functions of anti-disaster capability was to reestablish the learning capability of a system, which was particularly important in dealing with uncertainties in the operation of social ecosystems[21].

Based on the theoretical research above, the formation of anti-disaster capability in urban disaster is due not only to the effects of the inherent attributes of urban systems but also to the adaptive process of disasters after their 
occurrence. Anti- disaster capability shows the capability of an urban system to positively respond to disasters and quickly recover from them. As a result, Cutter et al. defined anti-disaster capability as the capability of urban systems to cope with and recover from disasters, including absorbing the destructive nature of such disasters, determining the internal conditions for dealing with such disasters, and analyzing the adaptive capability of urban systems to reorganize, change, and learn to respond to these disasters [22].

\section{Characteristics of anti-disaster capability}

The definitions of anti-disaster capability stated previously indicate that anti-disaster capability is a multidimensional concept. Cohen and other scholars proposed that antidisaster capability in urban disaster usually possessed three characteristics, namely, vulnerability presented by the urban system before disasters, resilience presented by the urban system during disasters, and adaptation presented by the urban system after disasters[23]. Because the urban disaster prevention and risk control is a large integrated system, prevention before disasters, resistance during disasters, and reconstruction after disasters are integral parts of urban disaster prevention and risk control systems. Under this circumstance, establishing a complete urban disaster prevention and risk control system to control urban disaster risk effectively is important. Therefore, studying these three characteristics of anti-disaster capability provides significant theoretical guidance for building a perfect urban disaster prevention and risk control system, which has become an emerging and important research topic.

\subsection{Vulnerability}

Vulnerability, which is derived from the Latin word "vulnerare", is used to describe the possibility of loss in the system. Scholars around the world have proposed up to 25 definitions of vulnerability[24]. The most representative of these definitions include the following: Mulligan defined vulnerability as a system state determined by natural, social, economic, and environmental factors, which may affect the fragility of urban systems in the face of disasters[25]. Levine defined vulnerability as the capability of an urban system to resist disasters determined by natural, social, economic, and environmental factors, and these factors determined the possibility and scale of the losses caused by a given disaster[26]. With the intensification of research on vulnerability, two branches of vulnerability theory have gradually formed.

(1) Category research on vulnerability, which can be mainly divided into physical and social vulnerability research. Physical vulnerability research emphasizes that vulnerability is closely related to the physical characteristics of disasters. It assumes that the occurrence of a disaster causes significant damage to all residents and socioeconomic assets in the affected areas. Thus, the frequency of the occurrence of disasters and the potential losses caused by disasters are mainly used to assess vulnerability[27]. Social vulnerability research focuses on the relationship between the urban system and the disaster-induced economic losses, which emphasizes the uneven distribution of the impacts of disasters on spatial areas. Social vulnerability is defined as "the ability to anticipate, respond, and defend against disasters and recover from disasters affected by the characteristics of the urban system itself'[28]. Furthermore, an increasing number of scholars have indicated that "physical vulnerability" is a necessary condition for the formation of disasters and is considered to be a hardware risk, which depends on the intensity of disasters. "Social vulnerability" is the source of the formation of disasters and is deemed to be a software risk, which depends on the characteristics of the urban system itself. The effects of disasters on the urban system are the results of the interaction between physical and social vulnerability.

(2) Composition research on vulnerability, which defines the composition of vulnerability as two key elements: exposure and sensitivity. Exposure usually refers to the population, property, and resource distribution exposed in disaster-affected areas, and it can be expressed by the locations and degree of impact of disasters[29]. The key factors in evaluating exposure to disasters include the characteristics of the disaster itself, environmental characteristics of buildings, the distribution of population and socioeconomic resources. The definition of sensitivity was proposed by Mechler et al., who believed that sensitivity was decided by human-environment conditions. According to them, sensitivity referred to the degree of losses in social and material conditions in the urban system when disasters occur[30]. The sensitivity of urban systems to disasters is related not only to the physical characteristics of the risk elements (e.g., geographical location, quality of buildings, and capacity of critical infrastructures to withstand disasters), but also to social, economic, and cultural conditions, political and institutional structures, risk awareness and preparedness of humans before disasters. These socioeconomic factors exert different effects on human sensitivity, and sensitivity changes according to the different coping capacities of affected communities.

\subsection{Resilience}

The word "resilience" is derived from the Latin word "resilio", which means "jump back". Initial research on this concept mostly focused on the theory of the ecologicalenvironmental system. Resilience is defined as the response of various mechanisms to external disturbances by resisting or changing to achieve and maintain the function and structure of the system at an acceptable level. In theoretical research on anti-disaster capability, resilience is defined as the capability of a community or organization to use all forces and resources to reduce the risks and effects of disasters. As the "internal vulnerability" of urban systems, resilience is an essential capability to predict, resist, or recover from the effects of disasters[31]. A resilient city can withstand the effects of disasters, adapt to the cycle and evolution of nature, live in harmony with nature, and automatically rebuild when necessary. No universally accepted concept of resilience has been established, but most scholars believed that resilience should include at least two characteristics as follows: (1) the degree of disturbance/influence of disasters and (2) the coping capability of the system. The degree of disturbance/influence of disasters is usually caused by the vulnerability of the urban system itself, which determines the resistance and adaptation of the urban system to disasters[32]. The coping capability of the system enables an urban system to minimize the effects of disasters, and it also refers to measures adopted to cope with the adverse consequences of disasters[33]. An increasing number of studies confirm that the resilience of urban systems to disasters is the degree of building and strengthening their learning and adaptive capability to reduce the vulnerability of urban systems. 


\subsection{Adaptation}

The term "adaptation" originates from research in biology and ecology. It mainly refers to the deviation in the behavior of human beings from their original states in response to environmental stress. In the early 20th century, adaptation to the environment was the consistent focus of anthropologists. Several scholars began to introduce adaptation to the study of anti-disaster capability as an important branch of research. Various adaptation conceptual theories were formed based on a pluralistic understanding of adaptation. However, all of these conceptual theories emphasized that the key to adaptation of urban systems was "the adjustment measures which were taken to adapt to changes". Thus, adaptation is mainly performed by urban systems to improve their inherent genetic properties or behavioral characteristics to better adapt to external environment/climate changes, including minimizing adverse effects and maximizing their potential opportunities[34]. With the in-depth study on the adaptation concept, four different research lines have been created as follows:

(1) Simulating the impact of disaster scenarios caused by various climate variations on different urban systems to evaluate the adaptation of urban systems based on the degree of mitigation or cancellation[35].

(2) Examining specific adaptation programs or measures adopted by a particular urban system when it is disturbed by disasters to deduce and analyze the differences of the key information in the urban system by simulating and deducing the implementation of the adaptation programs, to evaluate and compare the superiority and practicability of various alternative adaptation programs or measures, and to determine the "optimal" adaptation programs that can ensure the urban system fully adapt to the adverse effects of disasters[36].

(3) Building an assessment model using the evaluation indices selected by researchers to calculate the "adaptive score" of a particular country, region, or community, and to compare and analyze the relative adaptability differences of different countries, regions, or communities to the same disaster scenario[37].

(4) Analyzing the particular adaptation requirements of a particular region or community to identify which decisions or strategies can effectively improve the adaptation of regions or communities, to determine the specific implementation plan for improving the adaptation of regions or communities, and to implement the "bottom-up" decisionmaking process[38].

\section{Relationship among vulnerability, resilience, and adaptation}

Vulnerability, resilience, and adaptation are important features of anti-disaster capability in urban disaster. Thus, clarifying the relationship among these features is important in understanding and applying the definition of anti-disaster capability.

4.1 The relationship between vulnerability and resilience In current disaster risk and emergency management, studies on vulnerability and resilience are usually conducted simultaneously. Although research on vulnerability is earlier, more complicated and diversified than that on resilience, most of the definitions of vulnerability in early studies include resilience. For example, Coles et al. indicated that vulnerability referred to the sensitivity of urban systems when they exposed to disasters, and the capability of urban systems to adjust, recover, or make fundamental changes[39]. The definition of resilience is gradually separated from that of vulnerability because of the confusion and inconsistency of the definition of vulnerability and the deepening understanding of resilience. Buckle et al. conducted a qualitative assessment of vulnerability and resilience in Australian Emergency Management[40]. Current views on the relationship between resilience and vulnerability have been divided into three main categories: Several scholars, such as Young believed that resilience and vulnerability were two sides of the same coin, that was, an increase in the vulnerability of urban systems could lead to a reduction in their resilience. Thus, resilience and vulnerability possessed an inverse relationship[41]. Vulnerability was the possibility of urban systems being destroyed by disasters, and its opposite was the capability of urban systems to resist and recover from disasters, which was called resilience. If the urban systems were vulnerable, this also reflected that they had low resilience and vice versa. Several scholars, such as Miller, stated that the definitions of resilience and vulnerability were formed by the interaction of various complex factors, and they are both the attributes of urban systems, but not all[42]. Zheng defined resilience as the capability to cope and adapt to the pressure of disasters, and considered it as an integral part of vulnerability[43]. Karababa et al. suggested that vulnerability included resilience, and the resilience of urban systems was characterized by their capability to withstand disasters, which was an important component of vulnerability[44]. However, other scholars believed that vulnerability was completely unrelated to resilience. For example, Carpenter proposed that if vulnerability was viewed as the capability of urban systems to respond to disasters, then resilience and vulnerability should be regarded as two ends of a continuum[45]. Vulnerability was simply regarded as a type of environment, which led urban systems at risk (e.g., the risk of social, economic, policy, science and technology, population, and biophysics). So resilience and vulnerability had no relationship. Crane posited that the definition of resilience was in terms of the transformation of urban systems, but the definition of vulnerability referred to structural changes of urban systems, which were changes in the stable structure of urban systems. Thus, the fundamental differences between vulnerability and resilience were that vulnerability referred to the capability of urban systems to maintain their internal structure, whereas resilience referred to the recovery capability of dynamic urban systems without structural changes[46]. Thus, in general, vulnerability and resilience are similar to a double-helix structure which intersects at different social and spatial-temporal scales of urban systems. Vulnerability and resilience are inextricably linked and inseparable. In a broad sense, resilience includes the capability of urban systems to withstand disaster damages and recover from disasters. Accordingly, vulnerability is contained within the generalized concept of resilience. In a narrow sense, resilience is a process variable which reflects how urban systems adjust themselves to reduce indirect losses and recover to their normal statuses as soon as possible when a disaster has occurred. Resilience only includes the capability of urban systems to adjust, adapt, recover, and rebuild after disasters, which can be characterized by the recovery speed, the time required to recover to a new stable level, and the post-disaster recovery status. In determining the post-disaster recovery status of 
urban systems, the development degree of the pre-disaster status with the original normal speed in the recovery period should be considered, rather than making a static comparison with the pre-disaster status. Therefore, research on resilience is mainly used to make post-disaster recovery and reconstruction plans, with the purpose of determining which recovery plans can be achieved with half the effort (i.e., to identify the weakness of resilience building and the measures of efficient recovery after a disaster). Nevertheless, vulnerability is a state variable that reflects the extent to which urban systems transform damages into direct losses when disasters occur. Thus, vulnerability research is mainly for pre-disaster mitigation planning, which can clearly distinguish the definitions between vulnerability and resilience.

Therefore, for urban systems, several potential disastercausing factors exist before disasters occur, and urban systems present a certain degree of vulnerability when dealing with these disaster-causing factors. The higher vulnerability is, the greater the risk and losses are. The degree of resilience determines the actual condition of disasters. Regions or communities with high resilience can reduce disaster losses and recover to their normal state in a timely manner, whereas regions or communities with low resilience exhibit the opposite trend. In addition, due to the adjustment, adaptation, and learning capabilities of urban systems, resilience exerts a positive effect on subsequent disasters and can help people prepare, respond, and improve their disaster mitigation and emergency plans to further reduce vulnerability and risk. Hence, resilience possesses a positive feedback mechanism toward disasters. Vulnerability and resilience can thus be regarded as two important attributes of urban systems, which are determined by regional natural and socioeconomic systems. Vulnerability and resilience affect each other and run through the entire process of pre-disaster, during disaster, and post-disaster. Because the existence of economy, regional policy, population structure and quantity, and cultural differences in urban systems, the regional differences between vulnerability and resilience are evident and result in different effects of disaster-causing factors with the same intensity.

\subsection{Relationship between resilience and adaptation}

The relationship between resilience and adaptation is less clear because of the diversity of views. According to Uittenbroek et al., several scholars have equated adaptation with resilience[47]. For example, Gunderson regarded adaptation as the effectiveness exhibited by urban systems when faced with resilience changes[48]. Birkmann et al. used adaptation as a component of resilience which reflected the response of urban systems to disasters[49]. Forino et al. proposed adaptation as a collective capacity of human activists to manage resilience, which included reducing or excluding unexpected factors, creating new expected factors, and promoting the current urban system to transform to the expected status[50]. Other scholars believed that adaptation was a component of resilience that was related to the learning capability of urban systems to respond to disasters. Adaptation reflected the positive changes of urban systems in response to disasters[51]. Carreño et al. indicated that the development of adaptation of urban systems should be the necessary condition for improving resilience in the case of climate change[52]. The first purpose of urban systems in implementing relevant measures to improve adaptation to disasters is to reduce the disaster risk. The second purpose is to ensure that these measures provide alternative activities for vulnerable economic sectors. The third purpose is to ensure that proactive adaptation measures can support sustainable development and reduce poverty, particularly for disaster-prone areas. In general, resilience and adaptation interact and mutually reinforce each other. On the one hand, resilience can help urban systems adapt to changes in the post-disaster living environment as soon as possible and implement active measures to recover to pre-disaster living conditions. On the other hand, adapting to changes of disasters in urban systems is one of the characteristics of resilience, and the degree of adaptation also affects the degree of resilience.

\subsection{Relationship between adaptation and vulnerability}

In research area of disaster, research on adaptation has been closely linked with the study of vulnerability. With the indepth and extensive study of the independent conceptual system of adaptation and vulnerability, scholars have begun to investigate the relationship between adaptation and vulnerability and have achieved interesting results[53]. For example, Wang defined vulnerability as being composed of exposure, sensitivity, and adaptation[54]. Ebi argued that adaptation could affect the vulnerability of urban systems by adjusting their exposure and sensitivity, and because adaptation was a human reaction, it affected the physical and social elements of the urban system. Therefore, adaptation was regarded as the key factor for reducing vulnerability [55] Solecki proposed the indicators of vulnerability and adaptation of urban systems under the condition of global climate change[56]. Flanagan illustrated that the key to the relationship between adaptation and vulnerability depended on time scales and relevant disasters, and the vulnerability and potential vulnerability of urban systems, which were observed in medium and long terms, might primarily depend on their adaptation in anticipation of disasters[57]. Smit believed that adaptation and vulnerability were used in different domains and had different levels of definitions. For example, adaptation was the performance of the urban systems' adaptive capacity, which aimed to reduce the vulnerability of urban systems themselves[58].

\section{Evaluation of anti-disaster capability in urban disaster}

The definition of anti-disaster capability has been controversial for many years. Currently, research on antidisaster capability is still at the conceptual level, and only a few scholars can provide several methods to make the concept operational. In addition, most existed studies merely focused on quantitative research on the three characteristics of anti-disaster capability of urban systems, respectively. No major breakthroughs have been achieved in integration measurement, examination, and standardization research on anti-disaster capability in urban disaster[59].

\subsection{Progress of research on vulnerability assessment} Research on vulnerability assessment is considered as an important method to analyze the vulnerability of urban systems to disasters. Bergstrand argued that building an accurate vulnerability assessment model had an important reference value for developing specific and regional disaster management measures[60]. One of the typical vulnerability assessment models was the risk-disaster model, which was an initial vulnerability assessment model. This model analyzed and described the composition of vulnerability and its effect on urban systems[61]. The disaster pressure and 
release model was used to assess the distribution differences of vulnerability in time and space, and indicated that the root of these differences was the unequal distribution of power and resources in society[62]. The bidirectional structural model of vulnerability fully emphasized the essential characteristics of vulnerability and elaborated the differentiation and connection between the "external" and "internal" features of vulnerability[63]. Cutter et al. created the disaster-location model by investigating the potential vulnerability and social resilience of several specific regions. This model located and described various elements which affected vulnerability, and assessed the relationship and interaction among these elements[64].

\subsection{Progress of research on resilience assessment}

At present, research on resilience assessment mostly focuses on qualitative assessment. For example, Berkes et al. conducted a comprehensive qualitative assessment of the resilience of individuals and communities[65]. Mustafa assessed the effects of the social gaps between the rich and poor, and those of gender differences on resilience through field investigations, post-disaster statistics, and several other methods[66]. Therefore, qualitative assessment of resilience usually focuses on the importance and influencing factors of resilience, and how to enhance the disaster resilience of the society, organization, community, individual, and other aspects, which has a certain persuasiveness and operability. However, current research in this area is still in the initial stage, and not many mature research results have been obtained. By contrast, research on quantitative assessment includes the counter capacity index, which was used to assess the disaster resilience of countries[67]. Perrings used the nonlinear Kalman filter and error correction models to assess the productive capacity and resilience loss of agricultural ecosystems[68]. Wilson evaluated the resilience of communities from a social psychology perspective[69]. Bruneau et al. indicated that seismic resilience was composed of four interrelated dimensions, namely, technology, organization, society, and economy, which contained four attributes, namely, robustness, rapidity, redundancy, and resourcefulness[70]. Chan et al. constructed the social-economic loss model which was based on urban systems to assess the community resilience of lifeline systems to the damaging effects of earthquakes[71]. Thus, quantitative assessment of resilience mainly focuses on the simulation and evaluation of disaster reduction projects and other aspects, whereas only a few studies focus on the formation mechanism of resilience.

\subsection{Progress of research on adaptation assessment}

On the basis of in-depth research on adaptation conceptual theories, research on adaptation assessment is used to identify the degree of adaptation of a particular region or community, and to make relevant decisions or strategies to improve adaptation effectively[72]. Typical research on adaptation assessment includes Messner et al. argued that assessment of an adaptation strategy could be summarized as a systematic assessment of the influences caused by scheduled adaptation plans and strategies[73]. Fankhauser et al. believed that the core issue of such an assessment was to understand how adaptation measures affect urban systems or regions, which could support scientific decision making, and adaptation could be considered as a feedback or an administrative purpose for disaster management[74]. March used the balanced or statistical model to estimate and compare the extent of adverse effects on urban systems with or without adaptation, and the model could be used to determine the degree of risk of a specific climate change scenario[75]. Magis assumed a series of independent and discrete adaptation programs or measures to simulate and interpret the differences between key information in urban systems after adaptation projects had been implemented, and to assess the applicability and effectiveness of each adaptation project[76]. Helbron et al. used the aggregate function to integrate the assessment indices of adaptation, and calculate the "adaptation score" of specific countries, regions, or communities to assess their degree of adaptation [77]. Pearson et al. analyzed the research results on how to adapt to climate changes and mitigate the economic pressure caused by climate changes, and subsequently evaluated and analyzed the adaptation measures based on the assumptions of ecology and economy[78]. Currently, relevant quantitative research on adaptation only involved a preliminary discussion on adaptation assessment, and lacked a unified and widely accepted assessment system and index calculation method, and detailed quantitative assessment of the adaptation of urban systems still needed to be further investigated[79].

The complex internal structure of urban systems determines the characteristics of urban disasters as follows: First, urban disasters are numerous and diverse. A "swarm of disaster" situation often occurs as an inevitable result of the complicated factors and interlocks inner structure of urban disaster systems. Second, urban disasters have a chain of characteristics. When a disaster occurs, a series of other disasters are often derived. Finally, with urban economic and scientific development, new types and sources of disasters gradually increase. The main drawbacks of current quantitative research on certain characteristics of antidisaster capability of urban systems, which are used to develop risk control measures, are manifested in the following aspects when urban systems deal with disasters. First, the entire process of disaster prevention is incongruous with every section of disaster reduction. Current urban disaster risk control focuses on disaster relief, which causes an embarrassing situation of "curing the symptoms, not the disease". Second, the degree of integration of disaster reduction resources is low. Hence, horizontal communication among all functional departments is difficult to achieve. After the occurrence of a disaster, functional departments cannot communicate information in time, and disaster losses cannot be effectively controlled. Future urban disaster risk control systems, which are based on the integration and evaluation of anti-disaster capability, must aim to improve the comprehensive technology and management capability of urban disaster reduction, and enhance the overall urban disaster prevention plan. so the cities will have the comprehensive capability to resist disaster risks. At the same time, the risk control system must emphasize the feedback function of urban system to disasters, which means that in the different stages of urban disaster risks, the risk control system must adopt targeted measures to prevent disasters.

\section{Conclusions}

After summarizing and analyzing the concept, characteristics, and assessment model of anti-disaster capability, and reviewing existed research results and future research directions in this area, this study concluded with the current research of anti-disaster capability in urban disaster by 
collecting and analyzing a large number of global studies on such a capability. First, studies on anti-disaster capability had initially formed a consensus. Anti-disaster capability was defined as an inherent attribute of an urban system which highlighted the capability of urban system to resist, recover from, and adapt to disasters by organizing, changing, and learning. Second, a number of research results had been obtained to examine the respective concepts and interrelationships of the characteristics of anti-disaster capability (i.e., vulnerability, resilience, and adaptation). However, an in-depth discussion on the integration of antidisaster capability was lacking. Finally, assessment research on anti-disaster capability had mainly focused on each characteristic of anti-disaster capability to extract the main influencing factors, but lacked general quantitative criteria of anti-disaster capability.

The summary of existed literature showed that research on anti-disaster capability in urban disaster had formed a main blueprint that considered concept definition, system construction, and evaluation as a logical main line. In view of the important role of the anti-disaster capability in an urban system to respond to disasters, the future research and application of anti-disaster capability is important and urgent.
By strengthening the crossing and combination of various disciplines, such as disaster, geology, environment science, and ecology, particularly the effect of climate changes on anti-disaster capability in urban disaster, cross-disciplinary research should be conducted to investigate the formation mechanism, influencing factors, and basic data collection of anti-disaster capability, which can be used to actively promote the overall strength of urban disaster management.

\section{Acknowledgements}

The authors are grateful for the support provided by the National Natural Science Foundation of China (Grant Nos. 71601042 and 71603062), the Humanity and Social Science Youth Foundation of Ministry of Education of China (Grant Nos. 16YJC630071 and 16YJC630040) and the China Postdoctoral Science Foundation Funded Project (Grant No. 2016M601401).

Access article distributed under the terms of the Creative Commons Attribution License

\section{References}

1. Norris, F. H., Stevens, S. P., Pfefferbaum, S. P., Wyche, K. F., Pfefferbaum, R. L., "Community resilience as a metaphor, theory, set of capacities, and strategy for disaster readiness". American Journal of Community Psychology, 41(1-2), 2008, pp. 127-150.

2. Liu, J., Wang, S., "Analysis of the differentiation in human vulnerability to earthquake hazard between rural and urban areas: case studies in 5.12 Wenchuan Earthquake (2008) and 4.20 Ya'an Earthquake (2013), China”. Journal Housing \& the Built Environment, 30(1), 2015, pp. 87-107.

3. Mercer, J., Kelman, I., Taranis, L., Suchet-Pearson, S. "Framework for integrating indigenous and scientific knowledge for disaster risk reduction". Disasters, 34(1), 2010, pp. 214-239.

4. Deo, A. A., Ganer, D. W., Nair, G., "Tropical cyclone activity in global warming scenario". Natural Hazards, 59(2), 2011, pp. 771786.

5. Preston, B. L., Westaway, R. M., Yuen, E. J., "Climate adaptation planning in practice: an evaluation of adaptation plans from three developed nations". Mitigation and Adaptation Strategies for Global Change, 16(4), 2011, pp. 407-438.

6. Simelton, E., Fraser, E. D. G., Termansen, M., Forster, P. M., Dougill, A. J., "Typologies of crop-drought vulnerability: an empirical analysis of the socio-economic factors that influence the sensitivity and resilience to drought of three major food crops in China (1961-2001)". Environmental Science \& Policy, 12(4), 2009, pp. 438-452.

7. Schipper, L., Pelling, M., "Disaster risk, climate change and international development: scope for, and challenges to, integration". Disasters, 30 (1), 2006, pp. 19-38.

8. O'Keefe, P., Westgate\&Amp, K., Wisner, B. "Taking the naturalness out of natural disasters". Nature, 260(5552), 1976, pp. 566-567.

9. Gallopin, G. C., Gutman, P., Maletta, H., "Global impoverishment, sustainable development and the environment: a conceptual approach". International Social Science Journal, 41(3), 1989, pp. 375-397.

10. Stern, S., Uscherpines, L., Acosta, J., Chandra, A., Williams, M. V., "Building community resilience to disasters". Rand, 1(1), 2011, pp. 18-29.

11. Aldrich, D. P., Meyer, M. A., "Social capital and community resilience". American Behavioral Scientist, 59(2), 2014, pp. 254269.
12. Pomeroy, R. S., Ratner B. D., Hall S. J., Pimoljinda J., Vivekanandan V., "Coping with disaster: rehabilitating coastal livelihoods and communities”. Marine Policy, 30(6), 2006, pp. 786793.

13. Jongman, B., Hochrainerstigler, S., Feyen, L., Aerts, J. C. J. H., Mechler, R., "Increasing stress on disaster-risk finance due to large floods". Nature Climate Change, 4(4), 2013, pp. 264-268.

14. Yang, D., "Coping with disaster: the impact of hurricanes on international financial flows, 1970-2002". The B.E. Journal of Economic Analysis \& Policy, 8 (1), 2006, pp. 1903-1903.

15. Gaillard, J. C., Mercer, J., "From knowledge to action: bridging gaps in disaster risk reduction". Progress in Human Geography, 37(1), 2013, pp. 93-114.

16. Tyhurst, J. S., "Individual reactions to community disaster". American Journal of Psychiatry, 107 (10), 1951, pp. 764-769.

17. Chang, S. E., Shinozuka, M., "Measuring improvements in the disaster resilience of communities". Earthquake Spectra, 20(3), 2004, pp. 739-755.

18. Michelkerjan, E., Hochrainerstigler, S., Kunreuther, H., Linneroothbayer, J., Mechler, R., "Catastrophe risk models for evaluating disaster risk reduction investments in developing countries". Risk Analysis, 33(6), 2013, pp. 984-999.

19. Cimellaro, G. P., Reinhorn, A. M., Bruneau, M., "Framework for analytical quantification of disaster resilience". Engineering Structures, 32(11), 2010, pp. 3639-3649.

20. Rawls, C. G., Turnquist, M. A., "Pre-positioning of emergency supplies for disaster response". Transportation Research Part B: Methodological, 44(4), 2010, pp. 521-534.20.

21. Godschalk, D., Xu, C., "Urban hazard mitigation: creating resilient cities". Urban Planning International, 30(2), 2015, pp. 22-29.

22. Cutter, S. L., Barnes, L., Berry, M., Burton, C., Evans, E., Tate, E., Webb, J., "A place-based model for understanding community resilience to natural disaster". Global Environmental Change, 18(4), 2008, pp. 598-606.

23. Cohen, O., Leykin, D., Lahad, M., Goldberg, A., Aharonson-Daniel, L., "The conjoint community resiliency assessment measure as a baseline for profiling and predicting community resilience for emergencies". Technological Forecasting \& Social Change, 80(9), 2013, pp. 1732-1741.

24. Seeliger, L., Turok, I., "Towards sustainable cities: extending resilience with insights from vulnerability and transition theory". Sustainability, 5(5), 2013, pp. 2108-2128. 
25. Mulligan, M., Ahmed, I., Shaw, J., Mercer, D., Nadarajah, Y., "Lessons for long-term social recovery following the 2004 tsunami: community, livelihoods, tourism and housing". Environmental Hazards: Human and Policy Dimensions, 11(1), 2012, pp. 38-51.

26. Levine, C., "The concept of vulnerability in disaster research". Journal of Traumatic Stress, 17(5), 2004, pp. 395-402.

27. Aragóndurand, F., "Urbanisation and flood vulnerability in the periurban interface of Mexico City”. Disasters, 31(4), 2007, pp. 477494.

28. Kienberger, S., "Spatial modelling of social and economic vulnerability to floods at the district level in Buzi, Mozambique". Natural Hazards, 64(3), 2012, pp. 2001-2019.

29. Peduzzi, P., Dao, H., Herold, C., Mouton, F., “Assessing global exposure and vulnerability towards natural hazards: the disaster risk index". Natural Hazards \& Earth System Sciences, 9(4), 2009, pp. 1149-1159.

30. Mechler, R., Bouwer, L. M., "Understanding trends and projections of disaster losses and climate change: is vulnerability the missing link?" Climatic Change, 133(1), 2015, pp. 1-13.

31. Wein, A., Rose, A. Z., "Economic resilience lessons from the shakeout earthquake scenario". Earthquake Spectra, 27(2), 2011, pp. 559-573.

32. Bosher, L., "Built-in resilience through disaster risk reduction: operational issues". Building Research and Information, 42(2), 2014, pp. 240-254.

33. Ronan, K. R., Johnston, D. M., "Promoting community resilience in disasters". Springer Berlin, 8654 (5755), 2005, pp. 27-27.

34. Simmie, J., Martin, R., "The economic resilience of regions: towards an evolutionary approach". Social Science Electronic Publishing, 3(1), 2010, pp. 27-43.

35. Vafeidis, A. T., Nicholls, R. J., Mcfadden, L., Tol, R., S., J., Hinkel, J., Spencer, T., Grashoff, P. S., Boot, G., Klein, R. J.T., “A new global coastal database for impact and vulnerability analysis to sealevel rise". Journal of Coastal Research, 24(4), 2008, pp. 917-924.

36. Kathleen, S., Norris, F. H., Galea, S., "Measuring capacities for community resilience". Social Indicators Research, 99(2), 2010, pp. 227-247.

37. Sharma, C. S., Behera, M. D., Mishra, A., Panda, S. N., "Assessing flood induced land-cover changes using remote sensing and fuzzy approach in eastern Gujarat (India)". Water Resources Management, 25(13), 2011, pp. 3219-3246.

38. Whitman, Z. R., Wilson, T. M., Seville, E., Vargo, J., Stevenson, J. R., Kachali, H., Cole, J., "Rural organizational impacts, mitigation strategies, and resilience to the 2010 Darfield earthquake, New Zealand”. Natural Hazards, 69(3), 2013, pp. 1849-1875.

39. Coles, E., Buckle, P., "Developing community resilience as a foundation for effective disaster recovery". Australian Journal of Emergency Management, 19(4), 2004, pp. 6-15.

40. Buckle, P., "New approaches to assessing vulnerability and resilience". Australian Journal of Emergency Management, 15(2), 2000, pp. 8-14.

41. Young, O. R., "Institutional dynamics: resilience, vulnerability and adaptation in environmental and resource regimes". Global Environmental Change, 20(3), 2010, pp. 378-385.

42. Miller, F., Osbahr, H., Boyd, E., Homalla, F., "Resilience and vulnerability: complementary or conflicting concepts". Ecology \& Society, 15(3), 2010, pp. 634-634.

43. Zheng, F., Sun, C., "Climate change: new dimensions in disaster risk, exposure, vulnerability, and resilience". Progressus Inquisitiones De Mutatione Climatis, 8(2), 2012, pp. 79-83.

44. Karababa, F. S., Pomonis, A., "Damage data analysis and vulnerability estimation following the August 14, 2003 Lefkada Island, Greece, Earthquake". Bulletin of Earthquake Engineering, 9(4), 2011, pp. 1015-1046.

45. Carpenter, S. R., "Complex system: spatial signatures of resilience". Nature, 496(7445), 2013, pp. 308-309.

46. Crane, T. A., "Of models and meanings: cultural resilience in socioecological systems". Ecological \& Society, 15(2010), 2010, pp. 634-634.

47. Uittenbroek, C. J., Janssen-Jansen, L. B., Runhaar H. A. C., "Mainstreaming climate adaptation into urban planning: overcoming barriers, seizing opportunities and evaluating the results in two Dutch case studies". Regional Environmental Change, 13(2), 2013, pp. 399-411.

48. Gunderson, J., Crepeau-Hobson, F., Drennen, C., "Research to practice: a disaster behavioral health framework". Disaster Prevention \& Management, 21(5), 2012, pp. 572-583.
49. Birkmann, J., Garschagen, M., Tuan, V. V., Binh, N. T., "Rethinking the relationships of vulnerability, resilience, and adaptation from a disaster risk perspective". Natural Hazards, 70(1), 2014, pp. 609-627.

50. Forino, G., Meding, J. V., Brewer, G. J., “A conceptual governance framework for climate change adaptation and disaster risk reduction Integration". International Journal of Disaster Risk Science, 6(4), 2015, pp. 372-384.

51. Lin, B. B., Petersen, B., "Resilience, regime shifts, and guided transition under climate change: examining the practical difficulties of managing continually changing systems". Ecology \& Society, 18(1), 2013, pp. 28-37.

52. Carreño, M. L., Cardona, O. D., Barbat, A. H., “A disaster risk management performance index". Natural Hazards, 41(1), 2007, pp $1-20$.

53. Saavedra, C., Budd, W. W., "Climate change and environmental planning: Working to build community resilience and adaptive capacity in Washington State, USA". Habitat International, 33(3), 2009, pp. 246-252.

54. Wang, H., Su, W., "Evaluating and understanding top of the atmosphere cloud radiative effects in Intergovernmental Panel on Climate Change (IPCC) Fifth Assessment Report". Journal of Geophysical Research Atmospheres, 118(2), 2013, pp. 683-699.

55. Ebi, K. L., Yohe, G., "Adaptation in first- and second-best worlds". Current Opinion in Environmental Sustainability, 5(3-4), 2013, pp. 373-377.

56. Solecki, W., Leichenko, R., O’Brien, K., "Climate change adaptation strategies and disaster risk reduction in cities: connections, contentions, and synergies". Current Opinion in Environmental Sustainability, 3(3), 2011, pp. 135-141.

57. Flanagan, B. E., Gregory, E. W., Hallisey, E. J., Heitgerd, J. L., Lewis, B., "A social vulnerability index for disaster management". Journal of Homeland Security \& Emergency Management, 8(1), 2011, pp. 1-22

58. Mercer, J., Kelman, A., "Disaster risk reduction or climate change adaptation: are we reinventing the wheel? "Journal of International Development, 22 (2), 2010, pp. 247-264.

59. Hughes, T. P., Graham, N. A., Jackson, J. B., Mumby, P. J., Steneck, R. S., "Rising to the challenge of sustaining coral reef resilience". Trends in Ecology \& Evolution, 25(11), 2010, pp. 633642.

60. Bergstrand, K., Mayer, B., Brumback, B., Zhang, Y., “Assessing the relationship between social vulnerability and community resilience to hazards". Social Indicators Research, 122(2), 2015, pp. 391-409.

61. Hamza, M., Zetter, R., "Structural adjustment, urban systems, and disaster vulnerability in developing countries". Cities, 15(4), 1998, pp. 291-299.

62. Peguero, A. A., "Latino disaster vulnerability: the dissemination of hurricane mitigation information among Florida's homeowners". Hispanic Journal of Behavioral Sciences, 28(1), 2006, pp. 5-22.

63. Adikari, Y., Osti, R., Noro. T., "Flood-related disaster vulnerability: an impending crisis of megacities in Asia". Journal of Flood Risk Management, 3(3), 2010, pp. 185-191.

64. Cutter, S. L., Boruff, B. J., Shirley, W. L., "Social vulnerability to environmental hazards". Social Sciences Quarterly, 84(2), 2003, pp. 242-261.

65. Berkes, F., Ross, H., "Community resilience: toward an integrated approach". Society \& Natural Resources, 26(1), 2013, pp. 5-20.

66. Mustafa, D., "Reinforcing vulnerability? disaster relief recovery, and response to the 2001 flood in Rawalpindi Pakistan". Global Environmental Change Part B: Environmental Hazards, 5(3-4), 2003, pp. 71-82.

67. Rubin, O., Rossing, T., "National and local vulnerability to climate-related disasters in Latin America: the role of social assetbased adaptation". Bulletin of Latin American Research, 31(1), 2012, 19-35

68. Perrings, C., Stern, D. I., "Modeling loss of resilience in agroecosystems rangelands in Botswana". Environmental \& Resource Economics, 16(2), 2000, pp. 185-210

69. Wilson, G. A., "Community resilience, globalization, and transitional pathways of decision-making". Geoforum, 43(6), 2012 , pp. 1218-1231.

70. Bruneau, M., Chang, S. E., Eguchi, R. T., Lee, G. C., O'Rourke, T. D., Reinhorn, A. M., Shinozuka, M., Tierney, K., Wallace, W. A., von Winterfeldt, D., "A framework to quantitatively assess and enhance seismic resilience of communities". Earthquake Spectra, 19(4), 2003, pp. 733-752 
71. Chan, Y., Wilkinson, S., Brunsdon, D., Seville, E., Potangaroa, R., "An integrated approach: managing resources for post-disaster reconstruction”. Disasters, 35(4), 2011, pp. 739-765.

72. Folke, C., Carpenter, S. R., Walker, B., Scheffer, M., "Resilience thinking: integrating resilience, adaptability and transformability". Ecology \& Society, 15(4), 2010, pp. 299-305

73. Merz, B., Kreibich, H., Schwarze R., Thieken, A., “Assessment of economic flood damage”. Composites Science \& Technology, 65(5), 2010, pp. 735-740.

74. Fankhauser, S., Soare, R., "An economic approach to adaptation: illustrations from Europe". Climatic Change, 118(2), 2013, pp. 367-379.

75. March, A., "Cities, disaster risk and adaptation". Urban Policy \& Research, 32(4), 2014, pp. 519-520.
76. Magis, K., "Community resilience: an indicator of social sustainability”. Society \& Natural Resources, 23(5), 2010, pp. 401416.

77. Helbron, H., Schmidt, M., Glasson, J., Downes, N., "Indicators for strategic environmental assessment in regional land use planning to assess conflicts with adaptation to global climate change". Ecological Indicators, 11(1), 2011, pp. 90-95.

78. Pearson, T. R. H., Brown, S., Sohngen, B., Henman, J., Ohrel, S., "Transaction costs for carbon sequestration projects in the tropical forest sector". Mitigation \& Adaptation Strategies for Global Change, 19(8), 2014, pp. 1209-1222.

79. Kerr, L. A., Cadrin, S. X., Secor, D. H., "The role of spatial dynamics in the stability, resilience, and productivity of an estuarine fish population". Ecological Applications, 20 (2), 2010, pp. 497-507. 